УДК 332.3

\title{
РАЗВИТИЕ ЗЕМЕЛЬНЫХ ОТНОШЕНИЙ В КОНТЕКСТЕ УСТОЙЧИВОГО РАЗВИТИЯ И ЭКОЛОГИЧЕСКОЙ БЕЗОПАСНОСТИ РОССИИ
}

\begin{abstract}
Шафеев Руслан Шакирович канд.экон.наук, доцент

Смотрина Ольга Сергеевна канд.ист.наук, доцент ФГБОУ ВО «Оренбургский государственный аграрный университет»
\end{abstract}

Аннотация: В статье рассмотрены актуальные проблемы развития земельных отношений в рамках реализации концепций устойчивого развития и экологической безопасности. Актуальность рассматриваемой проблемы исследования определяется ролью земли как фактора определяющего устойчивое развитие государства и основного компонента природы, состояние защищенности которого влияет на многие процессы жизни общества. Целью исследования является анализ развития земельных отношений в России в рамках реализации концепций устойчивого развития и экологической безопасности. В результате исследования были установлены задачи государства по развитию земельных отношений, обеспечивающих достижение целей устойчивого развития и экологической безопасности.

Ключевые слова: земельные отношения, устойчивое развитие, экологическая безопасность, стадии роста, природоемкость экономики.

\section{DEVELOPMENT OF LAND RELATIONS IN THE CONTEXT OF SUSTAINABLE DEVELOPMENT AND ENVIRONMENTAL SECURITY IN RUSSIA}

\section{Shafeev Ruslan Shakirovich Smotrina Olga Sergeevna}

\begin{abstract}
The article deals with current problems of land relations development in the framework of implementing the concepts of sustainable development and environmental safety. The relevance of the research problem is determined by the role of land as a factor determining the sustainable development of
\end{abstract}


the state and the main component of nature, the state of protection of which affects many processes of society. The purpose of the research is to analyze the development of land relations in Russia within the framework of implementing the concepts of sustainable development and environmental safety. As a result of the study, the tasks of the state for the development of land relations that ensure the achievement of the goals of sustainable development and environmental safety were established.

Key words: land relations, sustainable development, environmental safety, growth stages, nature intensity of the economy.

Земля не является продуктом человеческого труда и относится к основному компоненту природы. Земельные ресурсы являются благом общества, и их развитие определяет многие экономические, экологические и социальные процессы. Задачей политики, направленной на реализацию концепции устойчивого развития должно стать обеспечение стабильности биологических и физических систем, к которым также относятся и земельные ресурсы. Актуальность рассматриваемой проблемы исследования определяется ролью земельных ресурсов в обеспечении целей устойчивого развития государства и экологической защищенности, которое влияет на многие процессы жизни общества. Целью исследования является анализ развития земельных отношений в России в рамках реализации концепций устойчивого развития и экологической безопасности.

Значению земельных отношений не только в экономике, но и в целом в жизнедеятельности человека посвящено множество научных публикаций [1, с. 13-18]. Трактовка роли земельных отношений осуществляется с позиции разных теорий и концепций: Богданов В.Л., Уварова Е.Л., Липски Е.А., Рязанцев И.И., Игнатьева И.А. Кухтин П.В [2-5].

В большинстве случаев под земельными отношениями понимается совокупность правовых, экономических, организационных, управленческих, административных и иных норм и правил, регламентирующих характер использования земли как многофункциональную основу общественного жизнеобеспечения и как основной фактор воспроизводственного процесса в обществе. С другой стороны земельные отношения - это отношения между государственными и общественными институтами, юридическими и физическими лицами по поводу владения и распоряжения землями, земельными участками, а также по поводу государственного управления земельными отношениями [6, с. 7-9]. 
Земельные отношения в современной России - результат длительного общественного развития практики использования и охраны земель, применяемых форм собственности и хозяйствования, приоритетных способов устройства территории. Они определяются национальными, социальными, экономическими и иными особенностями реализации функций земли как природного ресурса, средства производства, объекта имущества [7].

Экологическая роль территории России в планетарной геосистеме велика и является общепризнанным фактом. Комплексный показатель вклада России в сохранение устойчивости биосферы равен 10\% общепланетарного баланса, тогда как у Бразилии - 7\%, США и Канады по 5\%. Величина территории, составляющей $12,5 \%$ земной суши; масштаб диких лесов около $70 \%$ всего лесного массива планеты; переувлажненные земли и болота, регенерирующие атмосферный кислород и занимающие $8 \%$ территории страны - обусловливают тот факт, что российская территория выступает регионом компенсации глобальных антропогенных нарушений природы.

Земли, находящиеся в пределах Российской Федерации, составляют земельный фонд страны. Площадь земельного фонда Российской Федерации на 1 января 2019 года составила 1 712,5 млн. га без учета внутренних морских вод и территориального моря (рис. 1).

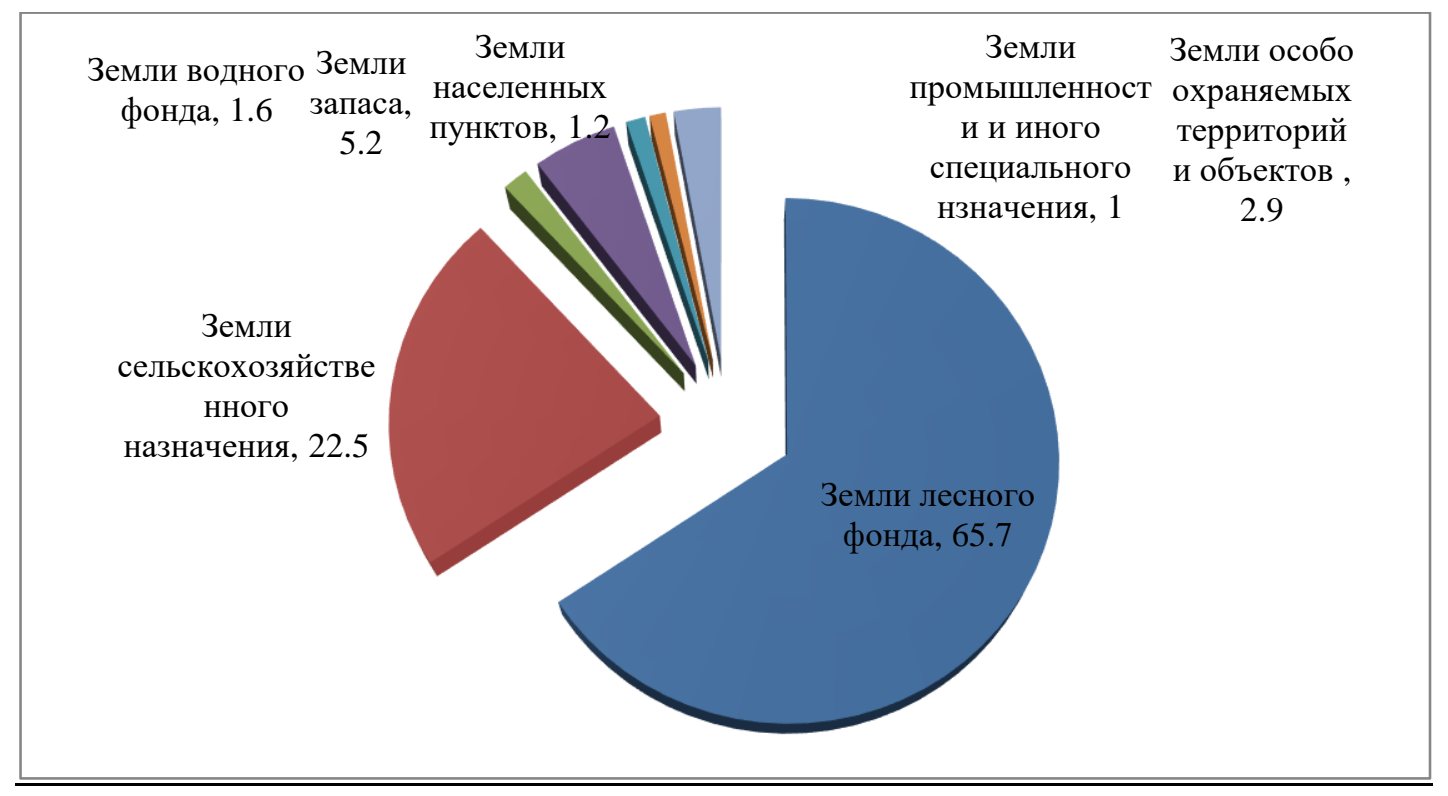

\section{Рис. 1 Структура земельного фонда Российской Федерации по категориям земель (по данным Росреестра)}


Несмотря на традиционно расточительное (со времен СССР) отношение к природно-ресурсному потенциалу, к настоящему времени в России сохранился крупнейший на планете массив естественных экосистем, который служит резервом устойчивости биосферы не только страны, но и всей планеты (табл. $1)$.

\section{Таблица 1}

Общая площадь природных экосистем в крупнейших странах мира

\begin{tabular}{|l|l|l|l|l|l|l|}
\hline Показатель & Россия & США & Китай & Канада & Бразилия & Австралия \\
\hline $\begin{array}{l}\text { Общая площадь страны, млн. } \\
\text { км }\end{array}$ & 17,1 & 9,57 & 9,33 & 9,22 & 8,46 & 7,64 \\
\hline $\begin{array}{l}\text { Доля площади естественных } \\
\text { экосистем, \% }\end{array}$ & 86 & 68 & 79 & 90 & 85 & 90 \\
\hline Доля площади лесов, \% & 47 & 30 & 14 & 54 & 58 & 19 \\
\hline
\end{tabular}

Источник: [8].

Значительную роль в обеспечении экологической безопасности земельных ресурсов играет система особо охраняемых природных территорий (ООПТ).

\section{Таблица 2}

Система особо охраняемых природных территорий России

\begin{tabular}{|c|c|c|c|c|c|}
\hline OOПТ & Заповедники & $\begin{array}{c}\text { Национальные } \\
\text { парки }\end{array}$ & $\begin{array}{c}\text { Государственные } \\
\text { природные } \\
\text { заказники }\end{array}$ & $\begin{array}{c}\text { Памятники } \\
\text { природы }\end{array}$ & $\begin{array}{c}\text { Дендрологические } \\
\text { парки и } \\
\text { ботанические сады }\end{array}$ \\
\hline $\begin{array}{c}\text { федерального } \\
\text { значения }\end{array}$ & 110 & 64 & 61 & 23 & 64 \\
\hline OOПT & $\begin{array}{c}\text { Природ } \\
\text { ные парки }\end{array}$ & $\begin{array}{c}\text { Государственн } \\
\text { ые природные } \\
\text { заказники }\end{array}$ & $\begin{array}{c}\text { Дендрологическ } \\
\text { ие парки и } \\
\text { ботанические } \\
\text { сады }\end{array}$ & $\begin{array}{c}\text { Памятники } \\
\text { природы }\end{array}$ & $\begin{array}{c}\text { ООПТ иных } \\
\text { категорий }\end{array}$ \\
\hline $\begin{array}{c}\text { регионального } \\
\text { значения }\end{array}$ & 117 & 2339 & 34 & 7861 & 758 \\
\hline OOПТ & \multicolumn{2}{|c|}{$\begin{array}{c}\text { Лечебно-оздоровительные } \\
\text { местности и курорты }\end{array}$} & \multicolumn{3}{|c|}{ ООПТ иных категорий } \\
\hline $\begin{array}{l}\text { местного } \\
\text { значения }\end{array}$ & \multicolumn{2}{|c|}{6} & \multicolumn{3}{|c|}{1506} \\
\hline
\end{tabular}

Источник: http:/oopt.aari.ru/filter/reset

В соответствии с «Основами государственной политики в области экологического развития России до 2030 года» стратегической целью государственной политики в области экологического развития является 83 
решение социально-экономических задач, обеспечивающих экологически ориентированный рост экономики, сохранение благоприятной окружающей среды, биологического разнообразия и природных ресурсов для удовлетворения потребностей нынешнего и будущих поколений, реализации права каждого человека на благоприятную окружающую среду, укрепления правопорядка в области охраны окружающей среды и обеспечения экологической безопасности. Экологическая безопасность - состояние защищенности природной среды и жизненно важных интересов человека от возможного негативного воздействия хозяйственной и иной деятельности, чрезвычайных ситуаций природного и техногенного характера, их последствий [9].

Экологические предпосылки являются одними из основных в концепции устойчивого развития [10, с. 495-498], поэтому можно предложить следующую модель взаимосвязи земельных отношений, экологической безопасности и устойчивого развития (рис. 2). 


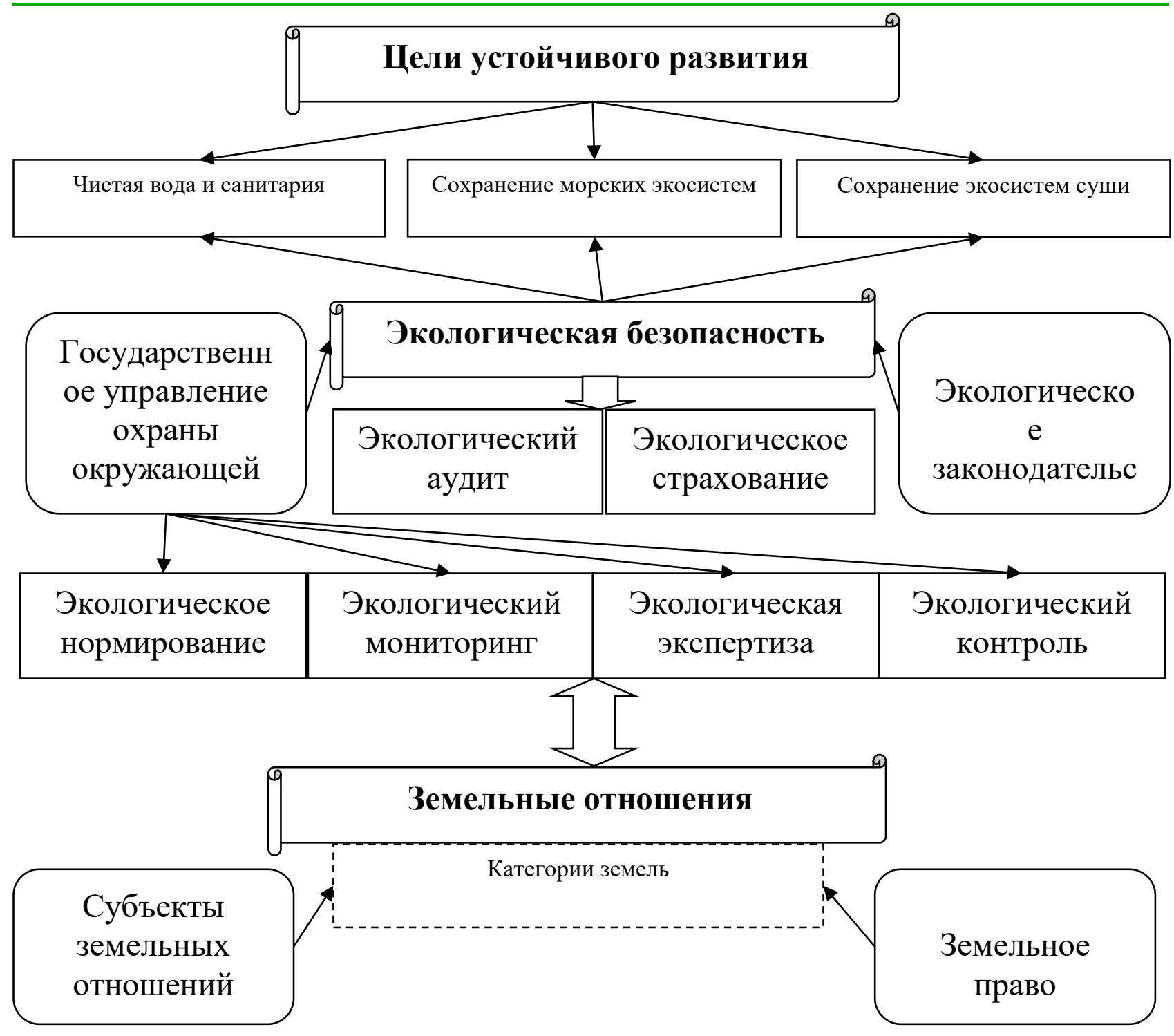

\section{Рис. 2 - Взаимосвязь земельных отношений, экологической безопасности и} устойчивого развития

Термин «устойчивое развитие» впервые прозвучал в 1987 году на заседании Международной комиссии $\mathrm{OOH}$ по окружающей среде. В научной литературе авторы используют классическое определение, в котором под устойчивым развитием понимается такое развитие, которое удовлетворяет потребности настоящего времени, но не ставит под угрозу способность будущих поколений удовлетворять свои собственные потребности. Устойчивое развитие включает в себя понятие потребностей, в т. ч. необходимых для существования беднейших слоев населения и понятие ограничений обусловленных состоянием технологии и организацией общества, 
накладываемых на способность окружающей среды удовлетворять нынешние и будущие потребности человечества [11, с. 113-119].

Рекомендации по разработке национальных концепций устойчивого развития были изложены в итоговых документах Конференции ООН по окружающей среде и развитию, проходившей в 1992 г. в Рио-де-Жанейро. В дальнейшем, в 2015 году ООН сформулировала 17 Целей устойчивого развития, обозначенные в «Повестке дня в области устойчивого развития на период до 2030 года» [12]. Они отражают идеологию устойчивого развития, сочетая в себе социальные, экономические и экологические приоритеты, а также содержат конкретные инструменты достижения обозначенных приоритетов.

В России давно осознается необходимость радикального изменения экспортно-сырьевой модели развития страны. Поэтому концепция устойчивого развития должна найти свое отражение в разрабатываемых долгосрочных документах развития страны. Сейчас при трактовке устойчивости преобладает узкий экономический подход, что противоречит долгосрочным целям развития страны. Государственная стратегия Российской Федерации, обеспечивающая переход национальной экономики к устойчивому развитию, изложена в Указе Президента РФ от 01.04.1996 г. № 440 «О Концепции перехода Российской Федерации к устойчивому развитию» [13]. Нормативный документ носит во многом декларативный характер и описывает основные направления обеспечения устойчивого развития национальной экономики, а также цели и задачи государственного регулирования экономического развития страны с точки зрения обеспечения интересов будущих поколений [14, с. 31-35].

Для осуществления перехода к устойчивому развитию необходима разработка соответствующих инструментов, представленных на рис. 3. 
программа технологического перевооружения промышленности за счет внедрения наилучших доступных технологий

система обеспечения экологически безопасного обращения с отходами система государственного

экологического мониторинга

(мониторинга окружающей среды) и

прогнозирования чрезвычайных ситуаций природного и техногенного характер эффективное участие граждан, общественных объединений, некоммерческих организаций и бизнессообщества в решении вопросов, связанных с охраной окружающей среды и обеспечением экологической безопасности система охраняемых природных территорий и сохранение биоразнообразия

\title{
Рис. 3 Инструменты реализации целей устойчивого развития
}

\author{
Источник [15].
}

Переход России к устойчивому развитию важен для повышения эффективности, прежде всего всей национальной экономики, с одной стороны, и в то же время для улучшения качества жизни людей, для раскрытия потенциала регионов - с другой.

Развитие земельных отношений в России регулируется Земельным кодексом Российской Федерации, согласно которой использование земель должно осуществляться способами, обеспечивающими сохранение экологических систем, способности земли быть средством производства в сельском хозяйстве и лесном хозяйстве, основой осуществления хозяйственной и иных видов деятельности [16, с. 62-64].

Для достижения целей устойчивого развития и обеспечения экологической безопасности в сфере земельных отношений российское правительство осуществляет меры по стимулированию внедрения инновационных технологий и развития экологически безопасных производств; минимизации ущерба, причиняемого окружающей среде при разведке и добыче полезных ископаемых, и рекультивации нарушенных земель; ликвидации 
вредных последствий антропогенного воздействия на окружающую среду; по развитию системы государственного экологического контроля и надзора, государственного мониторинга окружающей среды, земельных ресурсов, обеспечение соблюдения санитарно-эпидемиологических и санитарногигиенических стандартов в отношении питьевой воды, атмосферного воздуха и почв [16, с. 62-64].

Таким образом, развитие земельных отношений в контексте концепций устойчивого развития и экологической безопасности в России представляет собой изменение отношений между государством и обществом по поводу владения, пользования и распоряжения земельным фондом в целях обеспечения условий устойчивого развития и экологической защищенности.

\section{Список литературы}

1 Жавнерчик О.В. Категориальные основы экономико-экологической безопасности земельных отношений // Вестник Адыгейского государственного университета. Серия «Экономика». - 2012. - №4. - С. 13-18

2 Богданов В.Л., Уварова Е.Л. Роль и задачи земельных отношений на рынке земли Российской Федерации // Научное обеспечение развития АПК в условиях импортозамещения: сборник научных трудов международной научнопрактической конференции профессорско-преподавательского состава «Научное обеспечение развития сельского хозяйства и снижение технологических рисков в продовольственной сфере»: в 2-частях. - 2017. - С. 342-346.

3 Липски Е.А., Рязанцев И.И. Роль и значение характера земельных отношений для развития аграрного сектора экономики: теоретические положения и первоочередные задачи // Вестник АПК Ставрополья. - 2017. №3(27). - С. 71-75.

4 Игнатьева И.А. Роль международных договоров Российской Федерации в регулировании земельных отношений // Бизнес, менеджмент и право. - 2019. №2. - C. 23-29.

5 Кухтин П.В. Роль земельных ресурсов в государственной экономической системе // Интернет-журнал Науковедение. - 2014. - №2(21). C.50.

6 Борискова И.В. Общая характеристика земельных правоотношений в современной России // Фундаментальные и прикладные исследования: от 
теории к практике: материалы II международной научно-практической конференции, приуроченной ко Дню российской науки. - 2018. - С. 7-9.

7 Махотлова М.Ш., Карашаева А.С., Темботов 3.М. Регулирование государством земельных отношений // Аграрная наука. - 2015. - С. 4-7.

8 Государственный доклад «О состоянии и об охране окружающей среды Российской Федерации в 2015 году». - М.: Минприроды России; НИА Природа. - 2016. - 639 с.

9 Федеральный закон от 10.01.2002 N 7-Ф3 (ред. от 31.07.2020) «Об охране окружающей среды»

http://www.consultant.ru/document/cons_doc_LAW_34823/bb9e97fad9d14ac66df4b 6e67c453d1be3b77b4c/ (дата обращения: 27.11.2020).

10 Ражабов А. Х. О теоретических основах устойчивого развития // Молодой ученый. - 2016. - № 13 (117). - C. 495-498. - URL: https://moluch.ru/archive/117/32317/ (дата обращения: 27.11.2020).

11 Левина И.В. Понятие «устойчивое развитие». Основные положения концепции // Вестник ТГУ. - 2009 - №11(79). - С. 113-119.

12 Цели устойчивого развития ООН и Россия. Доклад о человеческом развитии в Российской Федерации. / Под ред. С.Н. Бобылева, Л.М. Григорьева 298 с. - Режим доступа: https://ac.gov.ru/files/publication/a/11068.pdf (дата обращения: 12.11.2020).

13 Указ Президента РФ от 01.04.1996 г. № 440 «О Концепции перехода Российской Федерации к устойчивому развитию» - Режим доступа: http://www.kremlin.ru/acts/bank/9120 (дата обращения: 27.11.2020)

14 Незамайкин В.Н. Стратегия устойчивого развития Российской Федерации // Финансы и кредит. - 2005. - №17 (185). - С. 31-35.

15 Анализ выполнения задач государственной политики в области экологического развития и соответствующих Поручений Президента Российской Федерации - М.: Всемирный фонд дикой природы (WWF), Национальное информационное агентство «Природные ресурсы» (НИАПрирода), 2016. - 54 с.

16 Гарипова, A. Р. Угрозы экологической безопасности в сфере землепользования // Молодой ученый. - 2019. - № 20 (258). - С. 62-64. - URL: https://moluch.ru/archive/258/59149/ (дата обращения: 27.11.2020). 